\title{
Article
}

\section{Exploring patient experiences of neo- adjuvant chemotherapy for breast cancer}

Beaver, Kinta, Williamson, Susan and Briggs, Jean

Available at http://clok.uclan.ac.uk/12346/

Beaver, Kinta ORCID: 0000-0002-6552-2323, Williamson, Susan ORCID: 00000002-9635-4473 and Briggs, Jean (2016) Exploring patient experiences of neo-adjuvant chemotherapy for breast cancer. European Journal of Oncology Nursing, 20 . pp. 77-86. ISSN 14623889

It is advisable to refer to the publisher's version if you intend to cite from the work. http://dx.doi.org/10.1016/j.ejon.2015.06.001

For more information about UCLan's research in this area go to http://www.uclan.ac.uk/researchgroups/ and search for < name of research Group>.

For information about Research generally at UCLan please go to http://www.uclan.ac.uk/research/

All outputs in CLoK are protected by Intellectual Property Rights law, including Copyright law. Copyright, IPR and Moral Rights for the works on this site are retained by the individual authors and/or other copyright owners. Terms and conditions for use of this material are defined in the policies page.

\section{CLoK}

Central Lancashire online Knowledge www.clok.uclan.ac.uk

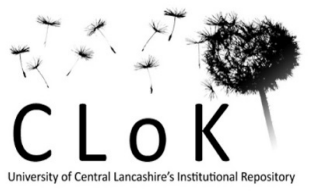


Title Page

Manuscript Title: Exploring patient experiences of neo-adjuvant chemotherapy for breast cancer

Authors:

Kinta Beaver ${ }^{1}$

kbeaver@uclan.ac.uk

Susan Williamson ${ }^{1}$

Swilliamson2@uclan.ac.uk

Jean Briggs ${ }^{2}$

DRJ.Briggs@bfwhospitals.nhs.uk

${ }^{1}$ School of Health, University of Central Lancashire, Preston, UK

${ }^{2}$ Department of Clinical Psychology, Blackpool Teaching Hospitals NHS Foundation Trust, Blackpool, UK

\section{Corresponding author:}

Kinta Beaver

School of Health, University of Central Lancashire, Brook Building, Preston PR1 2HE, Lancashire, United Kingdom

kbeaver@uclan.ac.uk

This manuscript has been accepted for publication in European Journal of Oncology Nursing. The manuscript will undergo copyediting, typesetting, and review of the resulting proof before it is published in its final form. Please note that during the production process errors may be discovered which could affect the content, and all disclaimers that apply to the journal apply to this manuscript.

DOI:http://dx.doi.org/10.1016/j.ejon.2015.06.001

Publication stage: In Press Corrected proof

Published online: June 132015 


\section{Abstract}

Background and purpose: Neo-adjuvant chemotherapy is recommended for 'inoperable' locally advanced and inflammatory breast cancers. For operable breast cancers, trials indicate no survival differences between chemotherapy given pre or post-surgery. Communicating evidence based information to patients is complex and studies examining patient experiences of neo-adjuvant chemotherapy are lacking. This study aims to explore the experiences of women who received neo-adjuvant chemotherapy for breast cancer. Methods: A qualitative approach using in-depth interviews with 20 women who had completed neo-adjuvant chemotherapy for breast cancer. Interview data were analysed using thematic analysis.

Results: The sample included a relatively young group of women, with caring responsibilities. Five main themes emerged: coping with the rapid transition from 'well' to 'ill', information needs and decision making, needing support and empathy, impact on family, and creating a new 'normal'. More support was needed towards the end of chemotherapy, when side effects were at their most toxic, and decisions about forthcoming surgery were being made. Some women were referred to psychological services, but usually when a crisis point had been reached.

Conclusion: Information and support would have been beneficial at key time points. This information is vital in developing services and interventions to meet the complex needs of these patients and potentially prevent late referral to psychological services. Specialist oncology nurses are able to develop empathetic relationships with patients and have the experience, knowledge and skills to inform and support women experiencing neo-adjuvant chemotherapy. Targeting key time points and maintaining relationship throughout neoadjuvant chemotherapy would be highly beneficial. 


\section{Key words:}

Breast cancer

neo-adjuvant chemotherapy

pre-operative chemotherapy

primary systemic therapy

patient experiences

qualitative

interviews

\section{Highlights}

- Communicating information to patients about neo-adjuvant chemotherapy is complex

- Studies examining patient experiences of neo-adjuvant chemotherapy are lacking

- This study explored patient experiences and made recommendations for practice

- Participants identified key times points when more information and support were required

- Meeting needs can potentially prevent late referral to psychological services 


\section{Exploring patient experiences of neo-adjuvant chemotherapy for breast cancer}

\section{BACKGROUND}

Chemotherapy has become a major cancer treatment modality, with increasingly toxic regimes aimed at improving outcomes (Del Mastro, Costantini, Morasso, Bonci, Bergaglio, Banducci et al 2002). Side effects of chemotherapy are numerous and can be immediate (e.g. facial and bodily flushing, hypotension, abnormal tastes and smells), short term (e.g. nausea, vomiting, gastrointestinal disturbances, stomatitis) and long term (e.g. alopecia, renal toxicity, sexual dysfunction, fatigue) (Dougherty, Bailey 2008). Given the severity of side effects, patients are likely to have a number of concerns, many of which may not be identified by nurses (Farrell, Heaven, Beaver, Maguire 2005), with discrepancies between patient and health care professional (HCP) perceptions of priority concerns (Mulders, Vingerhoets, Breed 2008).

While there is much literature on the physical side effects of chemotherapy, there is far less evidence on the psychosocial impact of chemotherapy. Chemotherapy is distressing and can have a long term impact on quality of life (Ganz, Desmond, Leedham, Rowland, Meyerowitz, Belin 2002). Women undergoing chemotherapy have reported priority concerns relating to current illness, the future, inability to do things and physical symptoms (Farrell, Heaven, Beaver, Maguire 2005). For breast cancer survivors the most important issues in relation to the impact of cancer and chemotherapy have been reported as fear of metastases, fatigue, consciousness of one's own vulnerability, hair loss and nausea (Mulders, Vingerhoets, Breed 2008). A qualitative study carried out in the UK with both male and female patients has shown that chemotherapy imposes drastic changes in social and emotional wellbeing as well as negative impacts on concentration and memory (Mitchell 2006). Mitchell (2013) reported on a desire to return to normality and regain control over life compounded by concerns over children. Although partners and spouses were reported as supportive, teenage children were described as unsupportive (Mitchell 2013). 
For women diagnosed with breast cancer who require adjuvant treatment, it is usual to offer chemotherapy after surgery. However, chemotherapy can also be given prior to surgery. Neoadjuvant chemotherapy (also referred to as pre-operative chemotherapy or primary systemic therapy) is commonly recommended for locally advanced and inflammatory breast cancers; cancers often defined as inoperable with a poor prognosis (Chia, Swain, Byrd, Mankoff 2008). The advantages of neo-adjuvant therapy in locally advanced and inflammatory breast cancers include earlier treatment of subclinical micro metastases, downstaging of the primary tumour (which may allow an inoperable tumour to become operable) and the ability to assess response to therapy(Chia, Swain, Byrd, Mankoff 2008). For some patients with locally advanced disease (but not inflammatory cancer) conservative surgery may emerge as a treatment option (Gralow, Burstein, Wood, Hortobagyi, Gianni, von Minckwitz 2008). A major disadvantage of pre-operative chemotherapy is the potential for considerable delay before surgery for patients whose tumours prove resistant to neo-adjuvant chemotherapy (Van der Hage, van de Velde, Mieog 2009). Neo-adjuvant chemotherapy for women with operable breast cancer is not clearly defined as yet although trials indicate no difference in survival between women treated pre or post-surgery (Van der Hage, van de Velde, Mieog 2009).

Selecting patients for neo-adjuvant therapy and communicating evidence based information is clearly complex, particularly for women diagnosed with more aggressive and/or advanced cancers. It can be argued that surgery, cutting out the problem, is readily understood whereas systemic treatment is more complex to understand (Beaver, Jones, Susnerwala, Craven, Tomlinson, Witham et al 2005). It has been shown that breast care nurses (BCN) are an important source of information and support, helping women cope with their disease (Beaver, Tysver-Robinson, Campbell, Twomey, Williamson, Hindley et al 2009; Cruikshank, Kennedy, Lockhart, Dosser, Dallas 2008,). However, for those women who receive neo-adjuvant treatment, it is not clear what their specific needs and concerns are and how services can best be organised to meet those needs. 
Research is lacking on the specific needs, concerns and experiences of women who receive neoadjuvant chemotherapy for breast cancer. Understanding these could help to target information, psychological support and interventions more appropriately. In addition, there is little research on how best to enable the decision making process for women who are faced with choices about whether to have chemotherapy before or after surgery. An understanding of the important factors determining patient preferences for different treatment options would enable more effective interventions to be developed and evaluated that would assist the decision making process. However, if neo-adjuvant chemotherapy is required due to the size or type of tumour and there are no choices presented then it is important to examine how this information is conveyed to patients and whether they fully understand the rationale behind clinical decisions.

\section{OBJECTIVE}

This study aimed to explore the experiences of women who received neo-adjuvant chemotherapy for breast cancer to determine psycho-social, information and support needs.

\section{METHODS}

Qualitative methods are well suited to exploring subjects where little is known and for gaining new insights and fostering deeper understanding of particular phenomena (Morse \& Richards 2002). As we could find no evidence of previous studies that examined the experiences of women with breast cancer who undergo neo-adjuvant chemotherapy, a qualitative study was justified as an initial exploratory step. We did not take a theoretically driven qualitative approach but chose a more generic approach as our intention was to focus more pragmatically on the clinical research question than the philosophical underpinnings. We acknowledge that there are interesting debates on theoretical versus generic approaches in qualitative research (Smith, Becker, Cheater 2011; Sandelowski 2000). We chose to use a qualitative descriptive approach as this involves remaining close to the data and is particularly suited to answering questions that have relevance for 
practitioners and policy makers (Sandelowski, 2000). Individual in-depth interviews were chosen as the most suitable method for obtaining rich and detailed data, exploring individual personal perspectives to generate an in-depth understanding of the particular subject area (Ritchie \& Lewis 2006).

\section{Study Location}

Study participants were recruited from four hospitals across Lancashire and South Cumbria in the North West of England that served an estimated population of 1.6 million residents in diverse geographical areas, allowing for recruitment of participants who may have had different experiences in terms of service provision and support.

\section{Sample and Sample Size}

Women were identified as suitable to take part in the study if they had undergone neo-adjuvant chemotherapy for breast cancer between May 2012 and April 2013. To maximise women's recall of events we did not recruit any individuals who were further than 12 months post chemotherapy. The number of interviews conducted was limited by study duration but was also guided by emergent findings and reaching a point at which no new information emerged.

\section{Access and Recruitment}

Ethical approval was obtained from the National Research Ethics Service in the UK and from the Research and Development departments at study sites. Specialist BCN's at the study locations were asked to identify suitable participants who met the inclusion criteria and to contact eligible women, describing the study and inviting participation. Potential participants were offered contact from a researcher, who discussed the study further and provided information sheets, consent forms and postage paid reply envelopes (for return of consent forms). Potential participants were asked to return a signed consent form, after which a suitable date and time for interview was arranged. 


\section{Interviews}

In depth face-to-face interviews were carried out with participants by two researchers experienced in qualitative data collection and analysis. All interviews were audio-recorded and transcribed using a professional transcribing service. An interview guide was constructed for the study to address the following areas: how information and choices about chemotherapy were communicated; patients experiences of neo-adjuvant chemotherapy and the support needed; patient views on the delay to surgery; views on adequacy of service provision; any concerns experienced during treatment (physical, psychological, social); psychological distress and referrals to psychological support services; information needs: what information was needed, sources of information (Figure 1). In addition, socio-demographic and treatment information was requested from study participants to describe the sample and to look for any emerging patterns in the data that could indicate predictors of need that could be explored in future work.

\section{Data Collection}

Study participants all chose to be interviewed in their own homes. Participant confidentiality was protected through the use of code numbers and the removal of all identifying information (e.g. names of HCPs, names of hospitals) from the data transcripts.

\section{ANALYSIS}

Two researchers independently coded the interview data using manifest content analysis procedures (Graneheim \& Lundman 2004, Morse \& Field 1998). NVIVO (a software package for managing and organising qualitative data) was used to assist with data management. Transcripts were read and initially open coded to begin identification of themes and categories. Any discrepancies in coding were resolved through review of the data and discussion until consensus was reached. Measures were taken to ensure the rigour of the research process as recommended in qualitative research 
(Denzin \& Lincoln 2000), including line-by-line analysis and regular review and de-briefing involving both coders. All quantitative data were entered into the data entry component of SPSS v20 and descriptive statistics were used to describe the study sample in terms of socio-demographic (e.g. age, marital status) and disease/treatment details (e.g. time from diagnosis, type of treatment).

\section{FINDINGS}

\section{Characteristics of the Study Sample}

Twenty women who had completed neo-adjuvant chemotherapy for breast cancer were interviewed across four different study locations. The mean age of the sample was 48 years, ranging from 30 to 67 years, and 11 had school age children. Women were a mean of 15.5 months from initial diagnosis, ranging from eight to 27 months. Other socio-demographic and disease/treatment related characteristics are shown in Table 1. A typical participant was married, working full time and had formal qualifications. The majority $(19 / 20,95 \%)$ had undergone a mastectomy; three of these women had both breasts removed by choice (i.e. removal of affected breast and contralateral prophylactic mastectomy of the unaffected breast). Eleven women (55\%) had required a hospital inpatient admission during the course of their treatment, usually in association with side effects of chemotherapy treatment. Half the sample had received formal counselling, either for themselves or for their children.

$<$ Insert Table 1 here $>$

\section{Themes}

Five major themes emerged from the data: coping with the rapid transition from 'well' to 'ill', information needs and decision making, needing support and empathy, impact on family and creating a new 'normal'. 


\section{Coping with the rapid transition from 'well' to 'ill'}

Participants had to live with the knowledge that the cancer was still present throughout treatment and, while they reported that the intention of the chemotherapy was to shrink the tumour, there were anxieties expressed about knowing that the cancer remained in their body.

'It was hard for me to bring the lump home and sleep with it and shower it' (ID 17)

'...there's always sort of hidden worries in there that whilst they're not actually taking the tumour away, then you're wondering whether it's getting bigger or what's happening to it, whether it's spreading or whatever, you know.' (ID 19)

Once chemotherapy commenced there was a rapid transition from being fit and healthy, having a full/part time job balanced with caring for young children and/or elderly parents to being 'ill' but retaining all the responsibilities associated with employment and parenthood. Neo-adjuvant chemotherapy was reported as an 'awful', 'frightening', 'horrendous' experience. Women felt unprepared for the immediacy of side effects (e.g. total hair and nail loss, oral mucositis, fatigue), while still dealing with the shock of the cancer diagnosis. Eleven women were admitted to hospital requiring treatment for chemotherapy side effects; four felt that they could not emotionally or physically continue with treatment and two reported that they refused to continue with chemotherapy and insisted on surgery. Enduring the final cycle of chemotherapy was a particularly difficult time; side effects had become extreme and women wanted it to be over but surgery still lay ahead. One woman described her treatment for breast cancer (neo-adjuvant chemotherapy, surgery and radiotherapy) as 'being poisoned, burnt and mutilated. You know it's medieval torture with a twist' (ID 16).

'I just thought, I just got to that point, no more. I don't want it anymore... I got to that point where I just...no, that's it, cut it out now.' (ID 15)

The women admitted to hospital had found the experience traumatic, reporting that they were 
being treated by generalist clinicians with little specialist cancer and/or chemotherapy knowledge.

Participants tended to be admitted to general medical wards, via emergency departments, where

staff did not understand their particular needs and were not able to respond appropriately.

'So I spent perhaps a week in the hospital. But was a bit... alone... because the hospital didn't know what they were doing because you get all these different doctors in the hospital and there's not one set. I had blisters in my mouth and everything... I kept saying, "I can't swallow, it's hurting." And they just kept saying, "Oh well, you'll be fine. You know, it's just normal." And I'm thinking.... Yeah, I know it's probably normal but... They gave me antibiotics in tablet form which I couldn't swallow, the nurse kept putting "Refused to take medication" which I wasn't refusing. It's just that I couldn't swallow any medication at all.' (ID 13)

The impact of chemotherapy on cognitive function was referred to by five women as 'chemo brain'.

They perceived this was not formally recognised as a condition, especially by oncologists, although

BCN's were more likely to acknowledge the existence of 'chemo brain'.

'When I ask about my chemo brain to my consultant, the answer is, "Oh it's just subjective. It doesn't exist." And you know there is no point discussing it any further because all the information is all anecdotal. ... I couldn't remember the name of Shakespeare's wife for goodness sake, I am an English teacher. I, you know I couldn't believe it, it was unbelievable. It was terrifying actually.'(ID 03)

'In fact I even gave up driving the car because I was... it was obvious to me that I wasn't on top of it as usual...l just wasn't... there was like a sort of fog in your mind which you.... And nobody prepared me for that at all, that aspect of it.' (ID 19)

Many participants had to continue their role as a mother to young children and attempt to continue working while undergoing chemotherapy and this may have added an additional burden to the negative experience.

'Oh god, I really am really poorly. Because you're floating along getting all the information off different people, and then the physical side of things happens. And that's when it sinks in, because you're seeing it....You see, I was perfectly healthy before. I used to go in the gym. I used to go outside climbing, swimming. And then, these things start falling off and it's like, "Oh, right. Now I'm ill." I wasn't ill, you know, not knowingly ill before, but now ...' (ID 11) 
There was a reluctance to get in touch with HCPs about problems as this could often mean travelling long distances to a specialist centre at a time when they felt too ill to travel. At this time participants would have welcomed a home visit or telephone contact.

'Or maybe even a home visit, you know. If you could make a phone call and say, "I am feeling dreadful, I've got this, this, and this," you don't want them to say, "Oh, come to [name of hospital]." It would be great if they could say, "Well, we have a community nurse who deals with this".' (ID 12)

\section{Information needs and decision making}

The initial, and unexpected, shock of diagnosis was disabling in terms of retaining and recalling information about treatment plans and side effects. Participants reported being given information at diagnosis but perceived that there were few further opportunities to ask questions, seek clarification or have information repeated. Most participants had met a $\mathrm{BCN}$ at the time of their diagnosis but this contact was then usually severed until chemotherapy had been completed; this could be many months later. Although participants commented that they needed more information about chemotherapy, it was acknowledged that it was difficult to know what information was needed until an individual had been through the experience. Not all participants wanted full information as they perceived this as potentially frightening. There were anxieties about asking questions in case the answer included yet more bad news.

'you're absorbing so little of some very important information. ...I knew I could pick up the phone but maybe it was one of those things well, they're busy, you know... I don't think you want bad news actually. You've heard enough.' (ID 12)

Participants understood that chemotherapy was being prescribed prior to surgery in order to shrink the tumour. Given this rationale it was difficult to understand why the whole breast was removed. Few indicated an understanding that chemotherapy was a systemic treatment. Participants reported receiving conflicting information from different HCP's and struggled to make sense of the overall treatment plan. 
'I mean they said that they wanted to reduce the size of the tumour. Fair enough. But in fact, it didn't make any difference, whether it was reduced or not, because they still did the same operation that they'd intended to do.' (ID 19)

Once chemotherapy had commenced, participants reported that it was challenging to obtain information. Chemotherapy nurses were knowledgeable about chemotherapy but the busyness of chemotherapy units was not conducive to asking questions. Community nurses were mentioned as being helpful and supportive but lacked information on side effects of treatment. Follow-up appointments with oncologists, and later with surgeons, were perceived as rushed with few opportunities to ask questions or seek clarification.

'When you go for an appointment at that stage, you see the consultants and to be quite honest he breezes through the door on one side and goes out the door at the other side, he barely stops in between, you know. ... he's really good but you don't have a chance to talk to him. So, then you got to grab the nurse but the trouble is he's then off to the next one and she's supposed to go with him. ... So, you feel like when you're actually there at an appointment, you don't get the chance to chat. And then that means that you've either then got to try and phone up and have a chat which sometimes is very difficult.' (ID 05)

Although participants had been given telephone numbers for the breast care nursing service and the chemotherapy unit and had been instructed to call if they were concerned or had queries, they were not sure whether what they were experiencing was 'normal' or which number they should call in a given circumstance.

'This was the very first session it [severe vomiting and mucositis] happened, so we weren't sure who to go to, do you know what I mean? Like if...because I had been going to my GP [General Practitioner] or go to chemo depart-...ring chemo department, would you ring? Would you...? We weren't sure about everything and then after that, he [husband] rang the breast care nurse.' (ID 13)

Other sources of information mentioned by participants included written information provided by HCP's, Internet sources and videos/DVD's that were watched in chemotherapy units. Although participants recalled being provided with written information, many reported that they did not read 
it or could not absorb it. However, it could be useful for family members or to refer to at a later date.

Participants searched for information on the Internet but this was generally perceived as being

frightening and anxiety provoking. However, on-line forums could be reassuring for some patients,

especially in respect of finding out if particular symptoms were 'normal'.

I was looking at the pile of literature that they give you. And I just thought that was...No, I don't want to look at it because I haven't got it. You know, it's like denial, I suppose. ... Well, I got talking to other people (on line). So, you kind of knew what to expect, and what was the norm, really. So, you knew that if you had certain symptoms, that other people would have these symptoms as well. So, it was really quite normal to be like that. So, that was reassuring.' (ID 20)

Only two participants reported being involved in the decision making process about whether to have chemotherapy before or after surgery. All remaining participants perceived that there had been no choice offered and accepted that chemotherapy would be given prior to surgery. Participants placed their trust in doctors to make the right decision, in the patients' best interests. Even if participants did not fully understand the treatment plan, they did not question it as they placed their trust in HCP's and perceived that they should do as they were told.

'But it's very, it's very difficult because obviously you tell other people, your family. And their reaction is, the same as ours is, why are you not going to chop it off, why are you going to send me home with my lump? . They know what they're doing, I don't. And I have to trust these people who are going to treat me. So, I didn't question. I didn't ask a single question until I was in about my fifth or sixth treatment of chemo, which was months down the line. I just turned up and did as I was told.' (ID 17)

As the chemotherapy treatment took place over a relatively long period of time participants had time to think about forthcoming surgery. Participants attempted to be more assertive about treatment options related to surgery than to chemotherapy. However, few were presented with surgical options as mastectomy was deemed necessary for 19 of the 20 women. Six women wanted to have both breasts removed following chemotherapy (i.e removal of the affected breast and contralateral prophylactic mastectomy of the unaffected breast); three realised their preference 
while two had one breast removed initially and secured agreement to have the remaining unaffected breast removed at a later date. Women who wanted both breasts removing had a clear rationale and did not want to risk recurrence of breast cancer and further surgery in the future. Participants reported that BCN's were supportive of their preference but it was challenging to gain agreement from surgeons who were reluctant to remove healthy breast tissue; women had to take an assertive stance and did not always succeed. A referral to a clinical psychologist was required if women wanted to have both breasts removed.

'I don't like to make bold statements but I know that had they said to me you're having the operation first, then chemo, then radiotherapy, I would only have had one (breast) removed. ....Having had the chemo first, the time it's taken to have that obviously gave me a chance to move through different phases of you know, how you feel and what you think ... Initially, my thoughts were I don't want to die now with my children being young. So, do what you're told to do. So, I did that. Once I'd got a bit through the chemo and a little bit more sane, and I suppose it had sunk in and things were working. I then thought, I stopped thinking about I don't want to die and I started thinking about how can I try and live.' (ID 17)

\section{Needing support and empathy}

Participants expressed a need for support and empathy in relation to the physical and psychological impact of diagnosis and treatment. The most important sources of support reported were family members. Few participants perceived that they had received support from HCP's while undergoing chemotherapy, especially in relation to psychological support. Only three participants mentioned attending face-to-face support groups, while one participant had accessed an on-line support group. Participants often reached crisis point before seeking support for the emotional impact of the diagnosis and treatment.

I think right from the beginning. I'm one of these people...I'm hugely independent. Don't like being trouble to anybody. And I think somebody should have sat me down and said "look, I think you need some help". It got to the stage where it was really bad before I asked for it. Maybe I should have asked for it sooner.' (ID 08)

Participants noticed that they were noticeably younger than other patients undergoing chemotherapy and wanted empathy and support from someone who would appreciate what they 
were going through, from someone who had experienced chemotherapy and was relatively young with young children.

'There's nothing like somebody who's been through it, you know, who can help because they know. ... I know my chemo wasn't any worse than anybody else's in that room. But I just look at them and they were old and I just think you can go home now ... you can sit and relax for the rest of the night. I have to go home and be mum and try and put a smile on my face and, you know, wipe bottoms or, you know, whatever ... and you just don't want to. You do want to; you want to be mum, but it's so, so exhausting. And I really wanted somebody else to talk to who'd been through that and know what it was like to cope with two children and chemotherapy.' (ID 06)

Participants did not tend to receive support from other patients in a similar position as neo-adjuvant chemotherapy was not a common treatment. However, it was considered helpful to have someone to talk to who had also experienced chemotherapy prior to surgery, even if not for treatment of breast cancer.

'... a gentleman who actually had bowel cancer but he had chemo before surgery. And his advice was probably the best because he told me exactly what each stage was going to be like. And it was exactly as he said and he gave me advice on how to cope. '(ID 10)

\section{Impact on family}

All participants commented on the importance of family for psychological support. The family unit was vital for providing support and seeking out explanations when participants initially felt unable to process the information they were being given. However, participants commented on their need to be strong, protecting young children, ageing parents and other family members from emotional pain or too much information that could be perceived as frightening and upsetting. This was challenging when faced with the physical and emotional burden of diagnosis and treatment.

'...my sister was visiting from America with the baby and it was the first time she'd been over. And I thought, I can't tell them all what's going on; I don't want this visit clouded by what's going on with me. ... and it was my daughter's birthday as well. And I'm bringing out the birthday cake and I just, started crying. I'm thinking, my God. This could be the last birthday I'm ever going to see. And everybody said, "what's the matter, what's the matter?" And I just go "I can't tell you, I can't tell you". And they all at that time thought it was because, 
whatever it was that I couldn't trust them with something. And it wasn't that. I just didn't want to cloud... upset them. ' (ID 09)

Participants were aware that their family members needed support themselves as some of the side effects of chemotherapy could be frightening, especially for young children. Two participants had sought psychological help for their children after it was suggested by their children's school teachers; this had been found to be beneficial.

'They've (children) been through too much already. I fainted on the toilet once and she (daughter) was the one that found me. So, you know, there was a time she didn't want me to go to the toilet. You know, they just...for little children, they've been through things that no children should have to go through.' (ID 06)

Although participants commented on the value of family support, they also acknowledged the added responsibility of trying to support family and care for young children and/or ageing parents while coping with diagnosis and treatment. Seeing the impact of the diagnosis and treatment on family members was painful for participants. None remembered receiving any help or support in how their role as a wife or a mother or a daughter might be affected or how they should break bad news to their children, husbands or parents. They knew their families would be upset but they had no framework for how to deal with their distress.

'So, I don't think perhaps there was much support for him (husband). I don't think there was. Or if it was there, we never looked for it. Maybe it's there and we didn't look for it. I don't know. Maybe he's... he was kind of always tagged on. Looking back on it now, I feel quite sorry for him actually because he was more or less ignored all the way through it. So even if I was speaking to a doctor or a nurse, (name of husband) was just there as a shadow. And I think actually, that's not a bit, not fair really, is it?' (ID 12)

'And then my son and he was only seventeen at that time, bless him, came to pick me up [from chemotherapy treatment] and I can remember seeing his face. And I just thought, I shouldn't have put him through this.' (ID 10)

\section{Creating a new 'normal'}

Participants reported that they had expected the side effects of chemotherapy to disappear once 
treatment had been completed and were surprised that they would have to cope with long term complications such as neuropathy that would affect their day to day function. The majority of participants had returned to work at the time of interview. Employers were generally reported as being understanding during treatment but less so once treatment had been completed, mistakenly assuming the employee would quickly return to a pre-diagnosis state of health.

"I handed another sick note in and she (employer) said "well what's the reason on it?" And I said, "Treatment for breast cancer." And she said, "But you're finished with treatment now." Well, no, I haven't thank you very much. So yeah I just felt like I was being pushed to go back in. And then I got told that if I didn't go back by a certain day, that was it. So I went back part time and that hasn't been very good.' (ID 01)

Participants wanted to get back to 'normal' but acknowledged that being diagnosed and treated for cancer had a massive physical and emotional impact, requiring a new normal to be created. Aspects of normality involved returning to work and looking after young children but the long term physical and emotional effects impacted on ability.

'...my psychological problems are how do I live with not looking over my shoulder for this coming back? And nobody could tell me it's not going to come back. I suppose that's... And the changes that it's made to me as well, you know; people aren't always happy if you don't return to the same person that you were, and I'm not.' (ID 06)

\section{DISCUSSION}

This study aimed to explore the experiences of women who received neo-adjuvant chemotherapy for breast cancer. Although neo-adjuvant chemotherapy is not as common as adjuvant chemotherapy, its use is increasing; to reportedly improve rates of breast conservation for women with operable disease (Herold \& Marcom 2008). In this study it was apparent that information and support needs were not always addressed and there was room for improvement to meet the specific needs of this group. 
Undergoing a toxic chemotherapy regime is accompanied by side effects for all oncology patients. However, for the women in this study, having chemotherapy prior to surgery brought an immediate transition from 'well' to 'ill'. It is arguable that experiencing surgery first (while distressing and painful) does not have the same 'illness' connotations and allows patients to prepare for adjuvant chemotherapy. These relatively young participants also had to deal with caring responsibilities while trying to maintain their previous level of employment. Side effects were evident for all participants and were especially severe for the 11 women who required admission to a hospital Emergency Department and/or in-patient admission. A Spanish study recently reported a $10.5 \%$ admission rate to hospital for chemotherapy related symptoms for patients who had been diagnosed and treated for breast cancer $(n=268)$; this was considered high (Baena-Canada, Estalella-Mendoza, Rosado-Varela, Exposito-Alvarez, Gonzalez-Guerrero, Diaz-Blanco, CortesCarmona et al 2012.). Although sample size was small in the current study, $55 \%$ had a hospital admission for chemotherapy side effects. It is not clear if hospital admissions could have been prevented if patients were clear who to contact for information and support. Those participants who were admitted to hospital encountered nurses on general hospital wards without cancer specific expertise and lacking understanding of the nature of chemotherapy side effects. Earlier intervention by a specialist practitioner could arguably have saved the costs of in-patient admissions and saved patients the anxiety of feeling that HCPs lacked the expertise to deal with their specific problems.

Participants described experiencing 'chemo brain' but also reported that HCPs were reluctant to acknowledge its existence. Recent research has produced interesting findings on 'chemo brain', arguing that it does exist (Holmes 2013, Hede 2008) and that chemotherapy (and other associated aspects of a cancer diagnosis) have a long lasting negative impact on cognitive function (Biglia, Bounous, Malabaila, Palmisano, Torta, D’Alonzo et al 2012; Koppelmans, Breteler, Boogerd Seynaeve, Gundy, Schagen 2012). However, not all women who undergo chemotherapy will 
experience cognitive deficits. Other factors, such as self-perception of mental decline, levels of anxiety and depression and passive coping style may account for some degree of cognitive impairment (Biglia, Bounous, Malabaila, Palmisano, Torta, D’Alonzo et al 2012, Reid-Arndt \& Cox 2012). Cognitive dysfunction was a particularly distressing side effect for participants who had responsibilities for young children and wanted to return to work post treatment. If HCP's do not acknowledge the existence of 'chemo brain' then it will be challenging at best for patients to obtain information and guidance on how to address the associated problems. Patients who perceive they have cognitive difficulties extending beyond the end of treatment may benefit from cognitive rehabilitation and coping strategies to improve memory (Hede 2008).

Surgery is the mainstay of cancer treatment for many types of cancer at primary diagnosis and it was difficult for women in this study to retain the cancer tumour and live with it for a number of months. It was also difficult to explain the rationale for delaying surgery to family members and friends. The rationale that had been presented to participants was a need to reduce tumour size, but almost all (19/20) participants had mastectomy rather than lumpectomy and participants themselves were not clear why chemotherapy had therefore been recommended prior to surgery. A more detailed discussion on the rationale for neo-adjuvant chemotherapy is necessary so that women have a full understanding of why chemotherapy is given before, rather than after, surgery. There was little understanding that chemotherapy was a systemic treatment or the difference between 'operable' and 'inoperable' tumours.

The extension of chemotherapy over a number of months allowed participants to shift from passive acceptance to a preference for active involvement in decision making. As the final cycles of chemotherapy were being administered and chemotherapy side effects were at their most toxic, participants knew that surgery was approaching. At this point more decisional support would have been welcomed. However, surgical options were limited. A recent French study reported that 
women who receive neo-adjuvant chemotherapy do not necessarily undergo more conservative surgery with $60 \%$ of 210 women undergoing mastectomy (Dabakuyo, Arnaud, Maingon, Causeret, Coudert, Fumoleau et al 2013). In the current study, 95\% (19/20) of participants had mastectomy, based on surgeon recommendation rather than patient preference. However, a number of women had asserted their surgical preferences and requested bilateral mastectomy as they did not want to deal with a recurrence of cancer in the unaffected breast and did not want to go through a period of severe 'illness' again. It has been reported that more women are choosing bilateral mastectomy for unilateral breast cancer (Yao, Stewart, Winchester, Winchester 2010). Preference for bilateral mastectomy in younger women has been associated with higher neuroticism, perceived risk for contralateral breast cancer and lower preference for lumpectomy with neuroticism viewed as an indicator of trait anxiety (King, O'Neill, Spellman, Peshkin, Valdimarsdottir, Willey et al 2013). Hence, it would seem vital to ensure effective communication about risk of recurrence and long term impact of surgical decisions in younger women undergoing neo-adjuvant chemotherapy as surgery approaches.

There is arguably a need for more accurate information for individual women on the impact of surgical treatment and more understanding on the part of HCPs on the long term impact of a cancer diagnosis on women's lives; for some women it was more important to reduce the risk of recurrence and/or further surgery than to conserve a healthy breast. However, the perception was that a bilateral mastectomy would reduce breast cancer recurrence. Contralateral prophylactic mastectomy greatly lowers the risk of developing cancer in the healthy breast, but there is no evidence of an increase in overall survival as an outcome (Tuttle, Habermann, Grund, Morris, Virnig 2007).The risk of systemic metastases from the primary cancer often exceeds the risk of developing a contralateral breast cancer (Yi, Meric-Bernstam, Middleton, Arun, Bedrosian, Babiera et al 2009). It is not clear from the interview data if women understood the recurrence risk. It has been argued that any estimate of contralateral risk not based on genetic evidence of risk is likely to be an over- 
estimate (Wood 2009). To minimise the risk of regrets in women contemplating contralateral prophylactic mastectomy, it is important that women receive information on contralateral breast cancer risk, other alternatives, and a realistic expectation of the cosmetic outcome (Montgomery, Tran, Heelan, van Zee, Massie, Payne et al 1999). There is a key timepoint towards the end of chemotherapy, when surgery is approaching, when women would most benefit from this information. However, it is at this time that little information and support is available and contact with BCNs is limited. More formal contact with a HCP towards the end of chemotherapy treatment when women are engaged in thinking about surgical decisions would be helpful.

Provision of information and support to women with breast cancer and their families is core to the role of the BCN (Jones, Leach, Chambers, Occhipinti 2010). It has been reported that BCN's provide continuity of care and are available throughout the experience to discuss treatment options and concerns (Halkett, Arbon, Scutter, Borg 2006). This is not reflected in the present study, which showed a clear lack of continuity as participants embarked on their chemotherapy treatment; continuity was re-established at the time of surgery. An Australian study reported that BCN's perceived themselves as important providers of psycho-social care and a link between patients and other services throughout the cancer journey; a role vital for the continuity of care (Jones, Leach, Chambers, Occhipinti 2010). In previous work it has been shown that BCN's are important sources of information and support for women who have completed their treatment, with continuity of care and building a trusting relationship shown to be important factors that patients value about contact with BCN's (Beaver, Williamson, Chalmers 2010; Beaver, Tysver-Robinson, Campbell, Twomey, Williamson, Hindley et al 2009). However, breast cancer is the most common cancer and BCNs have extremely high case loads, necessitating a focus on newly diagnosed patients who need support to cope with the cancer diagnosis. However, most patients in this study did not receive the support of $\mathrm{BCN}$ s while they were undergoing neo-adjuvant chemotherapy. While it is probably not feasible for $\mathrm{BCNs}$ to provide continued support to all women undergoing neo-adjuvant chemotherapy, it is 
important to acknowledge that physical, psychological and social needs are high during this period of time for both patients and their family members. Targeted communication at key time points (e.g. towards the end of chemotherapy) would have been beneficial for these women and may have prevented psychological problems escalating to a point of crisis.

Family members (partners and children) were a major source of support but also needed support. It has been reported that carers' emotional needs are similar to patients who undergo adjuvant chemotherapy. Carers go through a similar emotional journey in relation to the health-illness transition and provide support as a companion, protector, practical caregiver and advocate (Mcilfatrick, Sullivan, McKenna 2006). Hence, carers need to be acknowledged as valuable providers of support but also as needing support themselves to deal with the emotional impact of the diagnosis and treatment. Carers of women with breast cancer have been shown to have similar needs for information to those diagnosed and treated for breast cancer (Beaver \& Witham 2007), indicating that discussions about care and treatment should involve close family members. As recall and retention of information are limited at the time of initial diagnosis, having family members in attendance at consultations and engaging with them as a unit of care may enable information to be better recalled and retained.

Participants in this study appreciated support from those who would understand what they were experiencing. Participants were aware that they tended to be younger than other patients they encountered while undergoing chemotherapy. It has been reported that younger women with breast cancer experience higher levels of distress, are more likely to be depressed and cope less well than older women (Cimprich, Ronis, Martinez-Ramos 2002;). A recent literature synthesis on the experiences, needs and concerns of younger women with breast cancer reported underdeveloped social support networks and concerns regarding reproduction, fertility and sexuality (Adams, McCann, Armes, Richardson, Stark, Watson et al 2011). Younger women have to balance their own 
needs against the needs of their family, trying to protect children from the impact of the cancer and meet the financial demands of the household by maintaining paid employment (Adams, McCann, Armes, Richardson, Stark, Watson et al 2011). These age related issues were at the fore for participants in the current study. It is a cause for concern that women in the current study reported minimal contact with HCPs at a time of high need.

Support from others going through the same experience was perceived as beneficial, whether faceto-face or on-line. The use of the Internet as a form of information and support for people with cancer is becoming increasingly popular. A recent systematic review indicated that breast cancer survivors had a wide range of on-line support services available to them (Bender, JimenezMarroquin, Ferris, Katz, Jadad 2013). However, a recent pilot study on unmoderated Internet based peer support for women with breast cancer indicates that this form of support may not necessarily be beneficial (Salzer, Palmer, Kaplan, Brusilovskiy, Have, Hampshire et al 2010). Hence, it should not be assumed by HCPs that unmoderated on-line support will have a positive impact on patients' psychological health, even if patients report satisfaction with such a resource, and should not assume that this form of support can replace that provided by HCP's; more research is clearly needed in this developing area.

While this study focused on patient experiences of neo-adjuvant chemotherapy, it could be argued that some of the issues and concerns raised are similar to patients undergoing chemotherapy post surgery. A study carried out in the UK identified the concerns of 33 women with breast, ovarian, cervical and uterine cancer (Farrell, Heaven, Beaver, Maguire 2005). Although it was not reported if the women in the Farrell et al (2005) study had received chemotherapy pre or post surgery, the primary concerns related to the current illness, inability to do things, treatment and the future. These concerns have some similarities to the present study findings. Mitchell (2007) explored the impact of chemotherapy treatment for 19 patients. Again, it was not reported if patients had 
received chemotherapy per or post surgery but a number of the themes that emerged had resonance with our study findings. For example, patients in the Mitchell (2007) study indicated a desire for normality, concerns for young children and problems with concentration and memory. Hence, while some aspects of our findings are arguably unique to neo-adjuvant chemotherapy, such as living with the tumour and delays to surgery, other aspects may be common to all chemotherapy patients. More research is needed to clearly identify the needs of patients undergoing chemotherapy, both pre and post operatively.

\section{Limitations}

This was a small scale exploratory study and findings are not necessarily generalisable to other patients treated with neo-adjuvant chemotherapy for breast cancer. More work is needed in this area with a larger sample of women to confirm the generalisability of findings more broadly. The study was also limited in that it was conducted in the North West of England; sampling from more diverse geographical locations may have produced different findings. Study findings represent patient perceptions of their understandings. We do not know what participants were actually told about their cancer and the recommended treatment.

We did not collect data on stage of disease or type of breast cancer from patient medical notes so we do not know how many of our sample had inflammatory breast cancer, the most aggressive form of breast cancer that tends to affect younger women (Anderson, Schairera, Chena, Hance, Levine 2006). Given the young age of our sample it seems likely that some of these women had a diagnosis of inflammatory breast cancer; further work in this area should record histological details. The age of our sample was also a limitation in that older women were poorly represented. Hence, we were unable to explore the similarities and differences in views of younger and older participants. 


\section{CONCLUSIONS}

This small exploratory study provides important insights into the experiences of patients receiving neo-adjuvant chemotherapy for breast cancer. There were key time points at which information and support were most needed, but were lacking, particularly towards the end of chemotherapy. Continuity and support from $\mathrm{BCNs}$ is vital in developing services and interventions that will meet the complex needs of these patients and potentially prevent late referral to psychological services. Specialist BCNs have the ability to develop empathetic relationships with patients and the depth of experience, knowledge and skills to be able to answer the questions that most of these women had. Maintaining a relationship throughout neo-adjuvant chemotherapy would be ideal, although targeting key time points (e.g. towards the end of chemotherapy) would be highly beneficial.

\section{ACKNOWLEDGEMENTS}

Thanks are expressed to the patients who consented to take part in this study. Interviews required study participants to talk about their cancer journey and we fully appreciate participants sharing their recollections of difficult and distressing times. We would like to extend our thanks to all our clinical study collaborators including L Bracegirdle, S Guilfoyle, A Hindley, L Jones, M Ronson, S Susnerwala, A Thomas and D Tysver-Robinson. Thanks are expressed to the breast care nurses across the Lancashire region who assisted with recruitment. The study was funded by a project grant from the Rosemere Cancer Foundation, a charitable organisation based in Lancashire, UK. 


\section{REFERENCES}

Adams, E., McCann, L., Armes, J., Richardson, A., Stark, D., Watson, E., Hubbard, G., 2011. The experiences, needs and concerns of younger women with breast cancer: a metaethnography. Psycho-Oncology. 20(8), 851-861

Anderson, WF., Schairera, C., Chena, BE., Hance, KW., Levine, PH., 2006. Epidemiology of Inflammatory Breast Cancer (IBC). Breast Disease 22,9-23

Baena-Canada, JM., Estalella-Mendoza, S., Rosado-Varela, P., Exposito-Alvarez, I., GonzalezGuerrero, M., Diaz-Blanco, M., Cortes-Carmona, C., Ramirez-Daffo, P., Arriola-Arellano, E., Rueda-Ramos, A., Solana-Grimaldi, L., Benitez-Rodriguez, E., 2012. Use of health-care services during chemotherapy for breast cancer. European Journal of Cancer. 48(18), 33283334

Beaver, K., Jones, D., Susnerwala, S., Craven, O., Tomlinson, M., Witham, G., Luker, KA., 2005. Exploring the decision-making preferences of people with colorectal cancer. Health Expectations 8(2), 103-113

Beaver, K., Tysver-Robinson, D., Campbell, M., Twomey, M., Williamson, S., Hindley, A., Susnerwala, S., Dunn, G., Luker, K., 2009. Comparing hospital and telephone follow-up after treatment for breast cancer: a randomised equivalence trial. British Medical Journal 338, a3147.

Beaver, K., Williamson, S., Chalmers, K., 2010. Telephone follow-up after treatment for breast cancer: views and experiences of patients and specialist breast care nurses. Journal of Clinical Nursing 19(19), 2916-2924

Beaver, K., Witham, G., 2007. Information needs of the informal carers of women treated for breast cancer. European Journal of Oncology Nursing 11(1), 16-25

Bender, JL., Jimenez-Marroquin, MC., Ferris, LE., Katz, J., Jadad, AR., 2013. Online communities for breast cancer survivors: a review and analysis of their characteristics and levels of use. Supportive Care in Cancer. 21(5), 1253-1263

Biglia, N., Bounous, VE., Malabaila, A., Palmisano, D., Torta, DME., D’Alonzo, M., Sismondi, P., Torta, R., 2012. Objective and self-reported cognitive dysfunction in breast cancer women treated with chemotherapy: a prospective study. European Journal of Cancer Care 21(4), 485-491

Chia, S., Swain, SM., Byrd, DR., Mankoff, DA., 2008. Locally advanced and inflammatory breast cancer. Journal of Clinical Oncology 26(5), 786-790

Cimprich, B., Ronis, DL., Martinez-Ramos, G., 2002. Age at diagnosis and quality of life in breast cancer survivors. Cancer Practice 10(2), 85-93 
Cruikshank, S., Kennedy, C., Lockhart, K., Dosser, I., Dallas, L., 2008. Specialist breast care nurses for supportive care of women with breast cancer. Cochrane Database of Systematic Reviews. Issue 1. Art.No.:CD005634. DOI: 10.1002/14651858.CD005634.pub2.

Dabakuyo, TS., Arnaud, A., Maingon, P., Causeret, S., Coudert, B., Fumoleau, P., Arnould, L., Poillot, M., Arveux, P., Crehange, G., Bonnetain, F., 2013. Impact of neoadjuvant chemotherapy on survival in breast cancer patients in daily practice: a population-based study. European Journal of Cancer Care 22(5), 638-647

Del Mastro, L., Costantini, M., Morasso, G., Bonci, F., Bergaglio, M., Banducci, S., Viterbori, P., Conte, P., Ross, R., Venturini, M., 2002. Impact of two different dose-intensity chemotherapy regimens on psychological distress in early breast cancer patients. European Journal of Cancer 38(3), 359-366

Denzin, N., Lincoln, Y., Handbook of Qualitative Research 2000 (2nd ed) London: Sage.

Dougherty, L., Bailey, C., 2008. Chemotherapy. In Corner, J., Bailey, C., (Eds. 2nd Edition) Cancer Nursing: Care in Context. Blackwell Publishing Oxford; UK. pp 267-316

Farrell, C., Heaven, C., Beaver, K., Maguire, P., 2005. Identifying the concerns of women undergoing chemotherapy. Patient Education and Counseling 56(1), 72-77

Ganz, PA., Desmond, KA., Leedham, B., Rowland, JH., Meyerowitz, BE., Belin, TR., 2002. Quality of life in long term, disease-free survivors of breast cancer: a follow-up study. Journal of the National Cancer Institute. 94(1), 39-49

Gralow, JR., Burstein, HJ., Wood, W., Hortobagyi, GN., Gianni, L., von Minckwitz, G., Buzdar, AU., Smith, IE., Symmans, WF., Singh, B., Winer, EP., 2008. Preoperative therapy and invasive breast cancer: pathologic assessment and systemic therapy issues in operable disease. Journal of Clinical Oncology 26(5), 814-819

Graneheim, UH., Lundman, B., 2004. Qualitative content analysis in nursing research: concepts, procedures and measures to achieve trustworthiness. Nurse Education Today $24(2), 105-112$.

Halkett, G., Arbon, P., Scutter, S., Borg, M., 2006. The role of the breast care nurse during treatment for early breast cancer: the patient's perspective. Contemporary Nurse. 23(1), 4657.

Hede, K., 2008. Chemobrain is real but may need new name. Journal of the National Cancer Institute 100(3), 162-164

Herold, Cl., Marcom, PK., 2008. Primary systemic therapy in breast cancer: past lessons and new approaches. Cancer Investigation 26(10),1052-1059

Holmes, D., 2013. Trying to unravel the mysteries of chemobrain. Lancet Neurology 12(6), 533-534 
Jones, L., Leach, L., Chambers, S., Occhipinti, S., 2010. Scope of practice of the breast care nurse: A comparison of health professional perspectives. European Journal of Oncology Nursing 14(4), 322-327

King, L., O’Neill, SC., Spellman, E., Peshkin, BN., Valdimarsdottir, H., Willey, S,, Leventhal, KG., DeMarco, T., Nusbaum, R., Feldman, E., Jandorf, L., Schwartz, MD. 2013. Intentions for bilateral mastectomy among newly diagnosed breast cancer patients. Journal of Surgical Oncology 107(7),772-776

Koppelmans, V., Breteler, MM., Boogerd, W., Seynaeve, C., Gundy, C., Schagen, SB., 2012 Neuropsychological performance in survivors of breast cancer more than 20 years after adjuvant chemotherapy. Journal of Clinical Oncology 30(10), 1080-1086.

Mcilfatrick, S., Sullivan, K., McKenna, H., 2006. What about the carers?: Exploring the experience of caregivers in a chemotherapy day hospital setting. European Journal of Oncology Nursing 10(4), 294-303

Mitchell, T., 2007. The social and emotional toll of chemotherapy-patients' perspectives. European journal of Cancer Care. 16(1), 39-47

Montgomery, LL., Tran, KN., Heelan, MC., van Zee, KJ., Massie, MJ., Payne, DV., Borgen, PI., 1999. Issues of regret in women with contralateral prophylactic mastectomies. Annals of Surgical Oncology 6(6), 546-552.

Morse, JM., Field, PA., 1998. Nursing research: the application of qualitative approaches (2nd ed.). Cheltenham: Stanley Thornes.

Morse, JM., Richards, L. 2012. ReadMe First for a Users Guide to Qualitative Methods. $3^{\text {rd }}$ Edition. Sage Publications: London

Mulders, M., Vingerhoets, A., Breed, W., 2008. The impact of cancer and chemotherapy: perceptual similarities and differences between cancer patients, nurses and physicians. European Journal of Oncology Nursing. 12(2), 97-102

Reid-Arndt, SA., Cox, C., 2012. Stress, coping and cognitive deficits in women after surgery for breast cancer. Journal of Clinical Psychology in Medical Settings 19(2),127-137

Ritchie, J., Lewis, J., 2006. Qualitative Research Practice: A guide for social science students and researchers. Sage Publications: London.

Salzer, MS., Palmer, SC., Kaplan, K., Brisilovskiy, E., Have, TT., Hampshire, M., Metz, J., Coyne, JC., 2010. A randomized controlled study of Internet peer-to-peer interactions among women newly diagnosed with breast cancer. Psycho-Oncology 19(4), 441-446

Sandelowski, M., 2000. Whatever happened to qualitative description? Research in Nursing and Health. 23(4), 334-340 
Smith, J., Bekker, H., Cheater, F. 2011. Theoretical versus pragmatic design in qualitative research. Nurse Researcher. 18(2), 39-51

Tuttle, TM., Habermann, EB., Grund, EH., Morris, TJ., Virnig, BA. 2007. Increasing use of contralateral prophylactic mastectomy for breast cancer patients: a trend toward more aggressive surgical treatment. Journal of Clinical Oncology 25(33),5203-5209

Van der Hage, JH., van de Velde, CC., Mieog, SJSD., 2009. Preoperative chemotherapy for women with operable breast cancer. Cochrane Database of Systematic Reviews. Issue 2. Art No.:CD005002. DOI:10.1002/14651858. CD005002.pub2.

Wood, WC., 2009. Should the use of contralateral prophylactic mastectomy be increasing as it is? Breast 18 (Suppl 3),S93-5

Yao, K., Stewart, AK., Winchester, DJ., Winchester, DP., 2010. Trends in contralateral prophylactic mastectomy for unilateral cancer: a report from the National Cancer Database, 1998-2007. Annals of Surgical Oncology 17(10),2554-2562

Yi, M., Meric-Bernstam, F., Middleton, LP., Arun, BK., Bedrosian, I., Babiera, GV., Hwang, RF., Kuerer, HM., Yang, W., Hunt, KK., 2009. Predictors of contralateral breast cancer in patients with unilateral breast cancer undergoing contralateral prophylactic mastectomy. Cancer 115(5), 962-971. 
Table 1. Characteristics of the study sample $(n=20)$

\begin{tabular}{|c|c|c|}
\hline Characteristic & $\mathbf{n}$ & $\%$ \\
\hline \multicolumn{3}{|l|}{ Marital Status } \\
\hline Married/co-habiting & 16 & 80 \\
\hline Divorced/separated & 1 & 5 \\
\hline Never married & 3 & 15 \\
\hline \multicolumn{3}{|l|}{ Employment status } \\
\hline Working full time & 9 & 45 \\
\hline Working part time & 4 & 20 \\
\hline Retired from work & 2 & 10 \\
\hline Not working due to illness & 5 & 25 \\
\hline \multicolumn{3}{|l|}{ Socio-economic group (based on occupation) } \\
\hline Managers, directors and senior officials & 3 & 15 \\
\hline Professional occupations & 3 & 15 \\
\hline Associate professional and technical occupations & 4 & 20 \\
\hline Administrative and secretarial occupations & 6 & 30 \\
\hline Caring, leisure and other service occupations & 2 & 10 \\
\hline Elementary occupations & 2 & 10 \\
\hline \multicolumn{3}{|l|}{ Highest educational qualification } \\
\hline No formal qualifications & 2 & 10 \\
\hline School leaving exams/certificate/diploma & 10 & 50 \\
\hline University degree & 7 & 35 \\
\hline Missing data & 1 & 5 \\
\hline \multicolumn{3}{|l|}{ Ethnic group } \\
\hline White British & 17 & 85 \\
\hline Black African-Caribbean & 2 & 10 \\
\hline Indian & 1 & 5 \\
\hline \multicolumn{3}{|l|}{ Type of surgery received } \\
\hline Bilateral Mastectomy & 3 & 15 \\
\hline Mastectomy & 16 & 80 \\
\hline Lumpectomy/wide local excision & 1 & 5 \\
\hline \multicolumn{3}{|l|}{ Reconstructive surgery } \\
\hline Yes, completed & 2 & 10 \\
\hline No, but planned for future & 4 & 20 \\
\hline Uncertain at time of interview & 1 & 5 \\
\hline No, not planned & 12 & 60 \\
\hline Not applicable & 1 & 5 \\
\hline \multicolumn{3}{|l|}{ Radiotherapy } \\
\hline Yes & 20 & 100 \\
\hline \multicolumn{3}{|c|}{ Required hospital A\&E/in-patient admission during treatment } \\
\hline Yes & 11 & 55 \\
\hline No & 9 & 45 \\
\hline \multicolumn{3}{|l|}{ Received psychological counselling } \\
\hline Yes, for self only & 8 & 40 \\
\hline Yes, for self and children & 1 & 5 \\
\hline For children only & 1 & 5 \\
\hline No & 10 & 50 \\
\hline
\end{tabular}




\section{Figure 1. Interview Guide}

\section{Main areas to be explored:}

- Patients experiences of neo-adjuvant chemotherapy and the support they felt they needed at that time

- Any concerns experienced during treatment (physical, psychological, social)

Additional prompts:

Did they get the support they needed?

Who provided support?

What could have been improved?

What was done well?

- Patient experiences of how information and choices about chemotherapy were communicated

Additional prompts:

Were choices presented?

Who presented choices?

If the patient was involved in the decision making process what information was useful?

What could have been improved?

What decision was made and what were the important considerations?

- Information needs: what information was needed, sources of information

- Patient views on the delay to local therapy (if relevant)

Additional prompts:

\section{How was 'delay' perceived? \\ Positive and negative perceptions}

Any raised anxieties?

- Was any psychological distress experienced; referrals to psychological support services

- Views on adequacy of service provision: helpful and unhelpful aspects, could any aspects be improved?

- Any other important aspects of chemotherapy care and treatment that have not been discussed? 